\title{
Impact of Admixture and Rice Husk Ash in Concrete Mix Design
}

\author{
Dr. Shubha Khatri \\ (Civil Engineering Department, OPJIT, Punjipatra, Raigarh (C.G.), India)
}

\begin{abstract}
In this paper an attempt has been made to show the impact of Admixtures and Rice husk on concrete structures by conducting an experimental study in the laboratory to improve the cubic strength of concrete structures. Super plasticizer Conplast 430: G-8 as an Admixture is added in concrete mix design. Compressive strength of concrete cubes with Admixture at 7 and 28 days for $M-20$ grade has been found to be Superior as compare to without Admixture. Similarly, Rice husk ash as a partial replacement of cement is added in the concrete mix design and a detailed parametric study for 5\% and 15\% Rice husk has been carried out on compressive strength of concrete cubes for M-20 mix at 7 and 28 days. The results shows that compressive strength of concrete cubes has been improved by adding Admixture and Rice husk (as a partial replacement of cement) in the concrete mix design.
\end{abstract}

Keywords: Admixtures, Concrete, Cubic strength, Mix design, Rice husk ash

\section{INTRODUCTION}

Concrete is a composite man-made material mostly used as building binding material in construction era. Now-a-days concrete is used with advanced and improved technologies such as R.C.C. structures or F.R.C. structures to give extra ordinary strength and durability to the structures against sliding, cracking, buckling, overturning etc. Now-a-days in the field of Civil Engineering era a lot of work has been done related to the experimental study of compressive strength of concrete cubes in which only cement, sand, aggregates and water are used in the form of water-cement ratios with different grade of concrete with steel fiber concrete and silica fume and without Admixture [1-2]. But they did not use Super plasticizers as an Admixture. Admixture are the materials other than the three basic ingredients of cement-concrete-cement, aggregate and water added to the concrete mix before or during mixing to improve certain properties like setting time, workability, dispersion etc. To modify the mechanical properties Super plasticizer in the form of Admixture is used in this study.

Construction industry is one of the fastest growing sectors in India. Rapid construction activity and growing demand of houses has lead to the short fall of traditional building materials like bricks, cement, sand and wood. Demand of good quality of building materials to replace the traditional materials and the need for cost effective and durable materials for low cost housing has necessitated the researchers to develop variety of new and innovative building materials. Rice milling generates a byproduct known as husk and this husk is converted in to ash is known as rice husk ash. This RHA in turn contains around $85-90 \%$ silica. Silica is the basic component of sand which is used with cement for plastering and concreting. Few researchers have been studied the use of rice husk ash [3-4]. But they didn't use RHA as a partial replacement material or product with cement-sand-aggregate. In this paper a study has been carried out on compressive strength of concrete cubes using Rice husk 5\% and 15\% as a partial replacement of cement with M-20 grades of concrete.

This paper deals with the effects and impacts of Admixture and Rice-husk on compressive strength of concrete cubes of M-20 grades and also makes a comparative study for compressive strength of cubes with and without admixture and similarly with and without Rice husk ash by doing parametric analysis.

\section{METHODOLOGY}

Out of many test applied to the concrete, Compressive strength of concrete is the utmost important which gives an idea about all the characteristics of concrete. By this single test one judge that whether Concreting has been done properly or not. According to I.S. 456-2000 compressive strength of different grades of concrete is tabulated below in Table 1. Similarly, according to I.S. 456-2000 types of mixes are: (1) Nominal Mix (2) Standard Mix and (3) Designed Mix. Out of these, Standard Mix Design Method has been adopted here in this experimental study. In this paper only M-20 grade of Concrete Mix design has been prepared by weighing the ingredients cement, sand and aggregates with required water. Mixing was done by in a laboratory batch mixer. The specimens were cast in steel mould and compacted on a table vibrator. The specimens of 150 $\mathrm{mm} \times 150 \mathrm{~mm} \times 150 \mathrm{~mm}$ size of cube were cast for the determination of compressive strength. Curing of the specimens was started as soon as the top surface of the concrete in the mould was hard enough. Spreading wet gunny bags over the mould for 24 hours after the casting was carried out for the initial curing. The specimens were later placed immediately in water tank for further curing. 
Table 1 Compressive strength of different grades of concrete at 7 and 28 days

\begin{tabular}{|c|c|c|}
\hline Grade of Concrete & $\begin{array}{c}\text { Minimum compressive strength } \mathrm{N} / \mathrm{mm}^{2} \text { at } 7 \\
\text { days }\end{array}$ & $\begin{array}{c}\text { Specified characteristic compressive strength } \\
\left(\mathrm{N} / \mathrm{mm}^{2}\right) \text { at } 28 \text { days }\end{array}$ \\
\hline M15 & 10 & 15 \\
\hline M20 & 13.5 & 20 \\
\hline M25 & 17 & 25 \\
\hline M30 & 20 & 30 \\
\hline M35 & 23.5 & 35 \\
\hline M40 & 27 & 40 \\
\hline M45 & 30 & 45 \\
\hline
\end{tabular}

First of all six concrete cubes were cast and prepared with Super plasticizer Conplast 430: G-8 High range water reducing and retarding Admixture with Specific gravity : 1.24 to 1.26 with required quantity with respect to volume of cement used in standard mix design of M-20 grade concrete.

Similarly, twelve cubes were molded with required quantity of Rice husk ash in partial replacement of cement. In first stage six cubes of M-20 Mix with 5\% of RHA has been prepared and in the next stage $15 \%$ of RHA has been used in partial replacement of cement ingredient for preparation of next six cubes. These specimens were tested by compression testing machine after 7 days and 28 days curing.

This is a generalized methodology adopted one by one to determine the compressive strength of M-20 mix with use of Admixture and Rice husk ash respectively.

\section{EXPERIMENTAL ANALYSIS}

An experimental study has been carried out in laboratory to find the compressive strength of M-20 mix concrete cubes at 7 and 28 days by using Admixture and Rice husk respectively.

3.1 Procedure for making cubes with and without Admixture (Super plasticizer: Conplast 430 G-8)

(1) To perform experimental study in laboratory six concrete cubes with admixture and without admixture has been prepared in specimen of size: $15 \mathrm{~cm} \times 15 \mathrm{~cm} \times 15 \mathrm{~cm}$ for $\mathrm{M}-20$ grade respectively.

(2) Since for one cubic meter concrete mix $350 \mathrm{~kg}$ cement is required and for that admixture quantity is taken as 1.5litre. Super plasticizer Conplast 430: G-8 as an Admixture is added in concrete mix design by volume of cement used to mould three cubes according to M-20 grade ratio 1:2:4 (cement: sand: Aggregates) with required quantity of water with respect to $40 \%$ of cement. These cubes were placed in to water tank for curing of 7 and 28 days.

(3) Compressive strength of concrete cubes was determined in compressive testing machine.

(4) Results from the experimental work have been plotted in MS-Excel sheet after calculations.

3.2 Procedure for making cubes with and without Rice Husk Ash (RHA)

(1) Preparation of three cubes without RHA is similar as already explained in earlier section 1.1.

(2) To prepare next six cubes with $5 \%$ and $15 \%$ rice husk as partial replacement of cement, M-20 mix according to 1:2:4 ratios was designed. Ordinary Portland cement of 43 grades and Crushed lime stone coarse aggregate were used for the present experimental investigation. The rice husk ash used in cement concrete in experiment was prepared by burning the husk in open air at temp of about $1000^{\circ} \mathrm{C}$. When it was done in a closed chimney it did not remove its carbon content and produced a black powder, which could be hazardous for concrete when mixed.

(3) This concrete is poured in the moulds and tempered properly. After 24 hours these moulds are removed and test specimens are put in water for curing.

(4) These cubes were tested in compression testing machine after 7 days and 28 days curing. After that Load was applied gradually at the rate of $140 \mathrm{~kg} / \mathrm{cm} 2$ per minute till the Specimens fails.

(5) Results from the experimental work have been plotted in MS-Excel sheet after calculations.

\section{RESULTS \& DISCUSSIONS}

After conducting of experimental study on compressive testing machine to find out the compressive strength of concrete cubes with Admixture and Rice Husk ASH at 7 and 28 days following results is concluded here-

\subsection{Compressive Strength of Concrete Cubes with and without Admixture for M-20 Grade (1:2:4)}

Because standard ratio (1:2:4) is not sufficient for making 3 cubes hence material ratio is increased in the form of standard ratio as $(5 \mathrm{~kg}+12 \mathrm{~kg}+17 \mathrm{~kg}$.) i.e. cement, sand and aggregates. Water was taken 1.6 liters as $40 \%$ of cement. Since for one cubic meter concrete mix $350 \mathrm{~kg}$ cement is required and for that admixture 
quantity was taken as 1.5 litre. Hence for M-20 grade of Concrete mix design for 3 cubes, quantity of admixture calculated was $21 \mathrm{ml}$.

Results of Compressive strength of cubes with and without Admixture are listed below in Table 2. Results obtained from experimental analysis shows that by using Admixture in concrete mix design compressive strength of concrete cubes increases at 7 and 28 days respectively as compared to without Admixture shown in Table 1. It increases about $30 \%$ at 7 days and $50 \%$ at 28 days by inclusion of Super plasticizer as Admixture as compared to without Admixture and it is shown in Fig. 1.

Table 2 compressive strength of concrete cubes with Admixture

\begin{tabular}{|c|c|c|}
\hline \multirow{2}{*}{ No. of Days } & \multicolumn{2}{|c|}{ Mean Strength/Compressive Strength of Concrete Cubes( N/mm ${ }^{2}$ ) } \\
\cline { 2 - 3 } & With Admixture & Without Admixture \\
\hline 7 & 17.5 & 13.5 \\
\hline 28 & 28.7 & 20 \\
\hline
\end{tabular}

4.2 Compressive Strength of Concrete Cubes with and without Rice husk ash for M-20 grade (1:2:4)

Because standard ratio for M-20 mix (1:2:4) was not sufficient for making 12 cubes at 7 and 28 days respectively with $5 \%$ and $15 \%$ RHA as a partial replacement of cement so material ratio was increased in the form of standard ratio.

First of all for making of six cubes, ratio of cement: sand: aggregates were taken as $(9.13 \mathrm{~kg}: 13.01 \mathrm{~kg}$ : $28.29 \mathrm{~kg})$. Since in this ratio, $5 \%$ RHA was added due to which original ratio for mixing was taken as $(8.674 \mathrm{~kg}$ : $13.01 \mathrm{~kg}: 28.29 \mathrm{~kg}$ ). Quantity of RHA was $0.456 \mathrm{~kg}$. Quantity of water was added as $40 \%$ of cement.

Second time for making next six cubes with 15\% RHA ratio of cement: sand: aggregates were taken as (7.76 kg: $13.01 \mathrm{~kg}: 28.29 \mathrm{~kg}$ ). Quantity of RHA was taken as $1.37 \mathrm{~kg}$. Quantity of water was added as $40 \%$ of cement.

Table 3 compressive strength of concrete cubes with and without RHA

\begin{tabular}{|c|c|c|c|}
\hline \multirow{2}{*}{ No. of Days } & \multicolumn{3}{|c|}{ Mean Strength/Compressive Strength of Concrete Cubes ( N/mm²) } \\
\cline { 2 - 4 } & With 5\% RHA & With 15\% RHA & Without RHA \\
\hline 7 & 16.14 & 18.3 & 13.5 \\
\hline 28 & 25.46 & 30.5 & 20 \\
\hline
\end{tabular}

Results were obtained for compressive strength of concrete cubes at 7 and 28 days with 5\% and $15 \%$ RHA respectively are presented in Table 2 . These results are compared with Table 1 particularly with M-20 grade at 7 and 28 days results. These results clearly differentiate the increment in compressive strength of concrete cubes with and without RHA, shown in Fig. 2 and Fig. 3 respectively.

For 5\% RHA compressive strength of concrete cubes increases as $19.5 \%$ and $27.3 \%$ at 7 and 28 days respectively as compared to without RHA.

For 15\% RHA compressive strength of concrete cubes increases as $35.5 \%$ and $52.5 \%$ at 7 and 28 days respectively as compared to without RHA.

Fig. 4 shows a combined comparison graph of compressive strength of concrete cubes with 5\% and $15 \%$ RHA. In this figure compressive strength of concrete cubes increases continuously with $15 \%$ RHA as compared to 5\% RHA at 7 and 28 days respectively. It is about $13.38 \%$ at 7 days and about $19.78 \%$ at 28 days with respect to 5\% RHA.

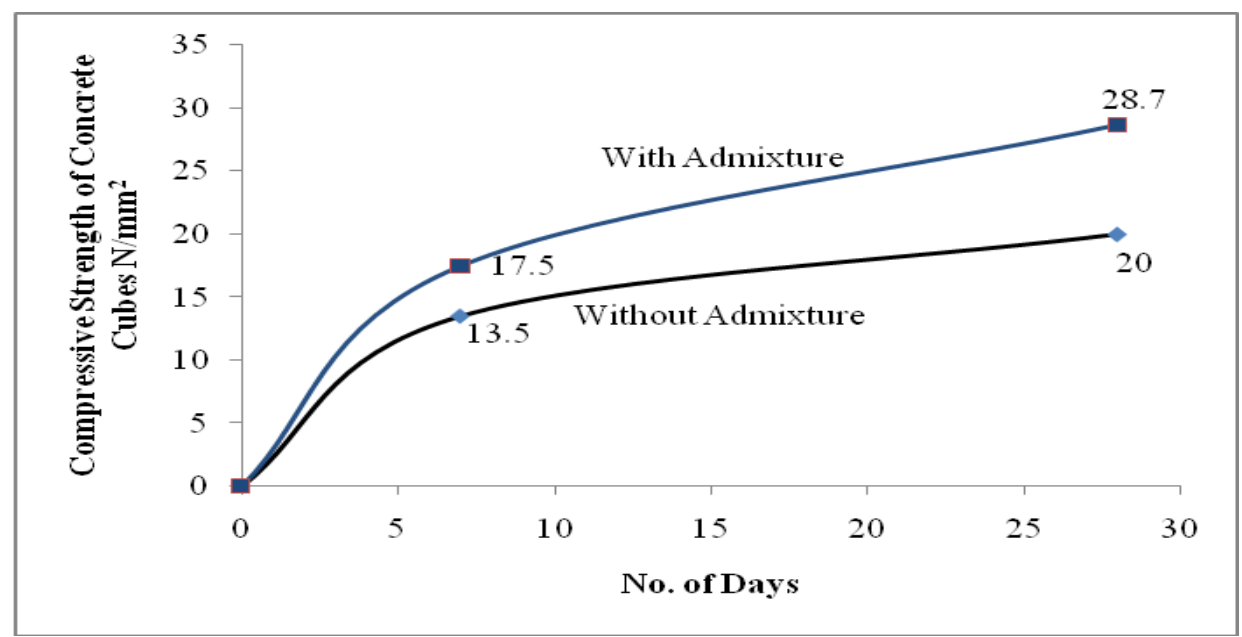

Fig.1 Comparison of compressive strength of concrete cubes with and without Admixture 


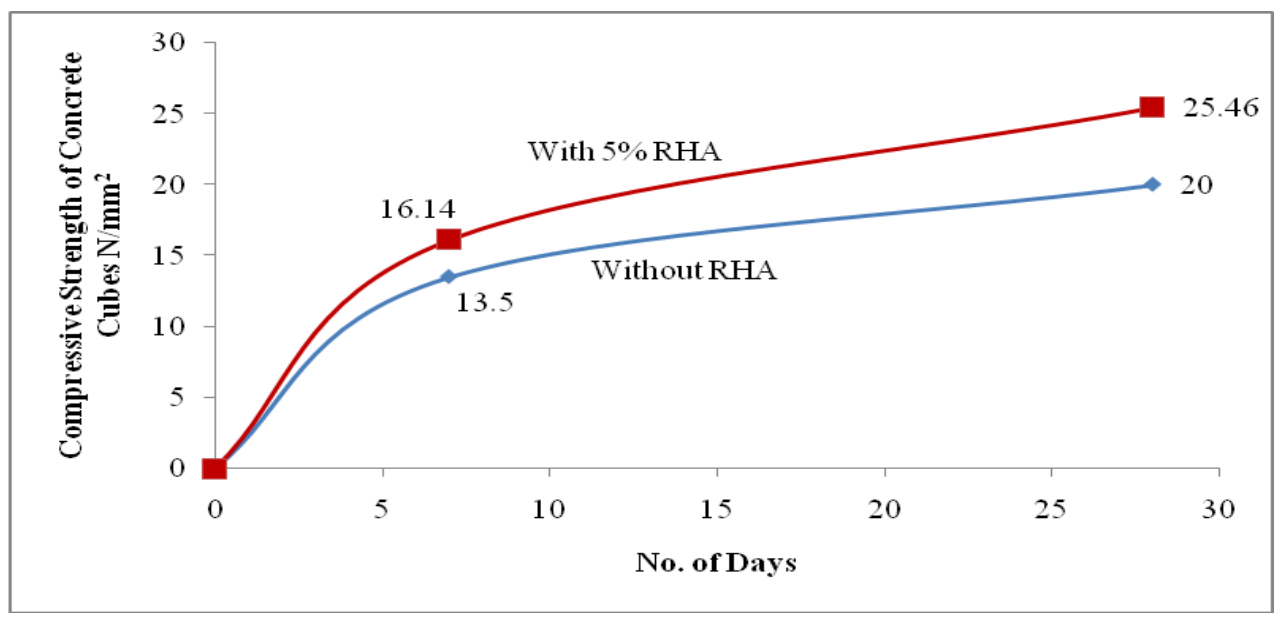

Fig.2 Comparison of compressive strength of concrete cubes with and without 5\% RHA

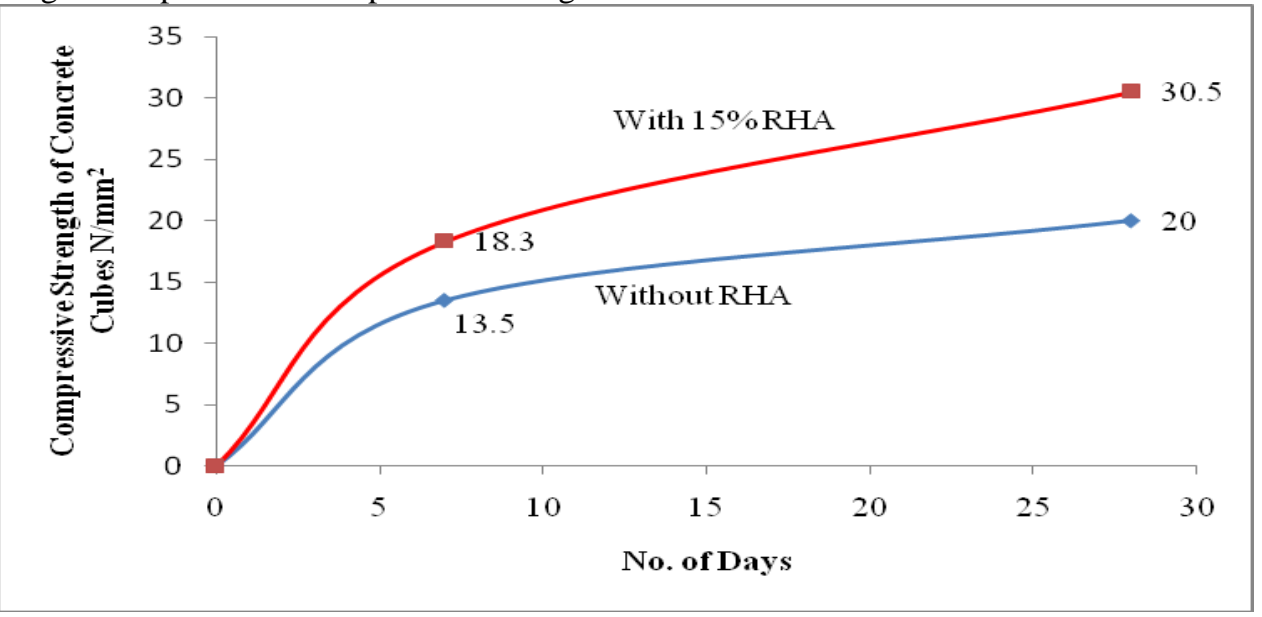

Fig.3 Comparison of compressive strength of concrete cubes with and without 15\% RHA

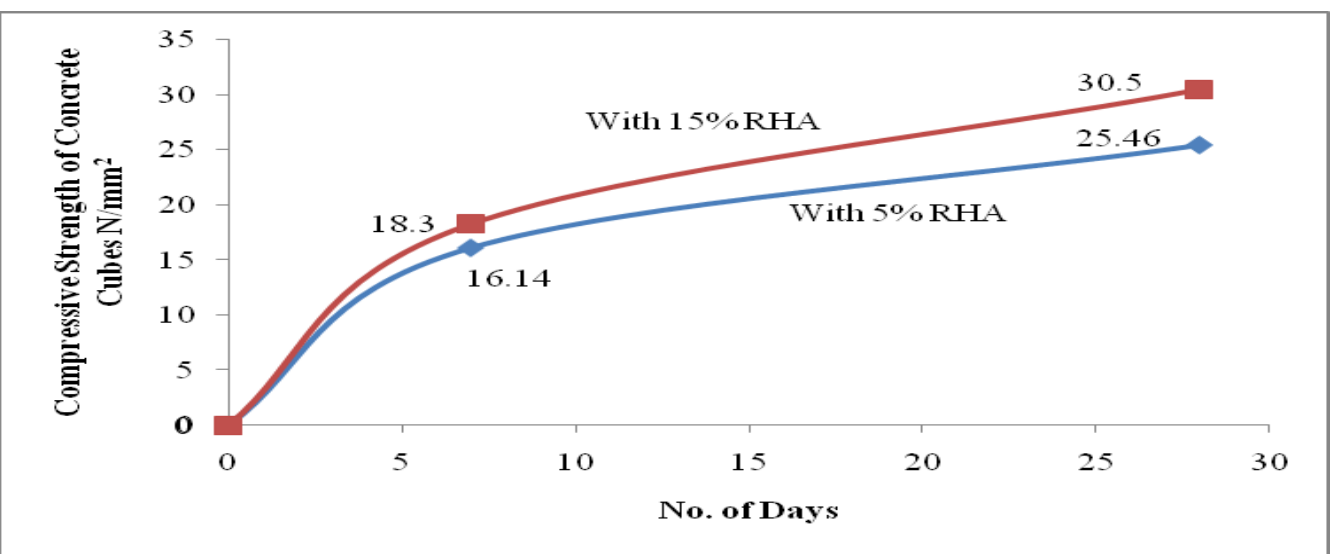

Fig.4 Comparison of compressive strength of concrete cubes with 5\% and 15\% RHA

\section{Conclusions}

In the present study, a simplified experimental study has been proposed and carried out for showing the impact of Admixture and Rice husk ash in concrete structure. The response of study has been presented in the form of compressive strength of cubes at 7 and 28 days. A comparison study has been carried out one by one 1) with and without Admixture and 2) with and without RHA. Based on this, the following generalized conclusions can be drawn:

1. Any variation in cubic strength of concrete cubes with and without admixture has been found to be significantly influenced with respect to number of days. It increases about $30 \%$ at 7 days and $50 \%$ at 28 days by inclusion of Super plasticizer Conplast 430: G-8 as an Admixture as compared to without Admixture. 
2. The influence of RHA on cubic strength of concrete cubes has been found to be sensitive with $5 \%$ and with $15 \%$ RHA as a partial replacement of cement.

3. An increment of about $19.5 \%$ and $27.3 \%$ at 7 and 28 days has been observed respectively with $5 \%$ RHA as compared to without RHA.

4. The compressive strength of concrete cubes has been found to be increased with $15 \%$ RHA as compared to without RHA. It is found to be increased about $35.5 \%$ and $52.5 \%$ at 7 and 28 days respectively.

5. A comparison study has also been carried out to show the effectiveness of 5\% and 15\% RHA. It has been observed that at $15 \%$ RHA compressive strength of concrete cubes increase about $13.38 \%$ at 7 days and about $19.78 \%$ at 28 days with respect to $5 \%$ RHA.

\section{REFERENCES}

[1] K. Parikh and D. J Dhyani. , Use of Micro Steel Fibers in Concrete with Innovative Supplementary Material Silica Fume- A Review, Indian Journal of Research, PARIPEX, Vol.2 (4), 2013, 143-145.

[2] M. Khaled and E. Ozgur, Effect of Cement Content and Water/Cement Ratio on Fresh Concrete Properties without Admixtures, International Journal of Physical Sciences, Vol.6 (24), 2011, 5752-5765.

[3] A.A. Godwin, E.E. Maurice, Akobo, I.Z.S and O.U. Joseph, Structural Properties of Rice Husk Ash Concrete, International Journal of Engineering and Applied Sciences, Vol.3 (3), 2013, 57-62.

[4] S. D. Nagrale, H. Hemant and R.M. Pankaj, Utilization of Rice Husk Ash, International Journal of Engineering Research and Applications (IJERA), Vol. 2 (4), 2012, 1-5. 